\title{
Influence of one porous layer insert on the transient heat transfer in a tall annulus in presence of large source terms
}

\author{
Fausto Arpino $^{1}$, Michela Ciccolella ${ }^{2}$, Gino Cortellessa ${ }^{1}$, Nicola Massarotti ${ }^{2}$, Alessandro Mauro ${ }^{2,3}$ \\ ${ }^{1}$ Dipartimento di Ingegneria Civile e Meccanica, Università di Cassino e del Lazio Meridionale, \\ G. Di Biasio 43, 03043 Cassino (FR), Italy \\ ${ }^{2}$ Dipartimento di Ingegneria, Università degli Studi di Napoli "Parthenope", Centro Direzionale, \\ Isola C4, 80143 Napoli, Italy \\ ${ }^{3}$ Università Telematica Pegaso, Piazza Trieste e Trento n.48, 80132 Napoli, Italy
}

Email: massarotti@uniparthenope.it

\begin{abstract}
This paper provides a sensitivity analysis on the influence of one porous layer insert on the transient behavior of natural convection in a tall annular enclosure in presence of large source terms. The porous medium which partially fills the cavity is characterized by a low value of the Darcy number, typical of insulating materials and metallic foams, often employed in heat exchangers and other engineering applications. A stabilized, fully explicit version of the Compressibility Based Scheme is here employed and validated against experimental data available in the scientific literature for steady and unsteady convection in vertical cylindrical enclosures. Several analyses are presented here by changing both the geometrical features of the cavity and the properties of the porous domain. The results of these analyses demonstrate that not only the thermo-physical properties of the porous medium but also the position and the thickness of the porous layer strongly affect the transient behavior of the convective phenomena occurring in the cavity.
\end{abstract}

Keywords: AC-CBS, Partially Porous Annulus, Low Darcy Number, Transient Natural Convection.

\section{INTRODUCTION}

Several real life applications involve free convection through media which can be represented as equivalent porous ones, such as heat insulating materials, chemical reactors, petroleum reservoirs, geothermal heat exchangers, etc. For this reason, the analysis of heat and mass transfer inside a porous medium has been extensively studied during the last decades and relevant dissertations on the subject can be found in ref. [1-2]. In the scientific literature, steady-state natural convection in vertical porous annuli has been widely investigated; in particular, experimental data-sets have been provided by Reda [3] and Prasad et al [4-5] whereas numerical studies based on the assumption of the Darcy model have been presented in ref. [6-12]. Among them, notable are the works of Badruddin et al. [10-12], which analyze the influence of the thermal radiation on the steady free convection in fully porous vertical annuli, taking into account viscous effects [10] and adopting a non-local thermal equilibrium model [12]. A hybrid solution has been developed by Hasnaoui et al. [13]; moreover, several models have been developed in order to consider nonDarcian effects. In particular, a Brinkman-extended model has been presented in ref. [14-16], the only Forchheimer term is introduced in [17] whereas both terms are taken into account by Marpu [18].
Moreover, transient natural convection in porous vertical annuli has not been extensively investigated: only Sankar et al. [19] and Jha and Yusuf [20] derived numerical [19] and semianalytical [20] solutions for time-dependent problems.

Few numerical works are available for the analysis of both steady [21-24] and transient [25-27] natural convection in partially porous annuli; the available time dependent solutions deal with open-ended [25], and with closed [26-27] vertical partially porous annuli with vertical porous inserts with variable properties and positions. These works focused on the stability of the flow in the cavity for high values of Darcy number, without providing any detailed sensitivity analysis of the influence of the porous layer on the transient heat transfer for low values of Da.

Therefore, this work focuses on this topic: several analyses are presented by changing both the geometrical features of the cavity and of the porous insert, both the properties of the porous medium.

\section{MATHEMATICAL MODEL}

In the present paper, the authors employ the generalized porous medium model, taking into account Whitaker's volume averaging method for the derivation of the dimensionless 
governing equations, and the hypothesis of local thermal equilibrium for the porous medium modeling [27]. Under these hypotheses, the governing equations of the generalized porous medium model, written in a cylindrical coordinate system, are the following:

$$
\frac{1}{r} \frac{\partial\left(r \cdot u_{r}\right)}{\partial r}+\frac{\partial u_{z}}{\partial z}=0
$$

$$
\begin{aligned}
& \frac{1}{\varepsilon} \frac{\partial u_{r}}{\partial t}+\frac{1}{\varepsilon^{2}}\left(u_{r} \frac{\partial u_{r}}{\partial r}+u_{z} \frac{\partial u_{r}}{\partial z}\right)=-\frac{\partial p_{f}}{\partial r}+ \\
& \sqrt{\frac{\operatorname{Pr}}{R a}} \frac{J}{\varepsilon}\left[\frac{1}{r} \frac{\partial}{\partial r}\left(r \frac{\partial u_{r}}{\partial r}\right)-\frac{u_{r}}{r^{2}}+\frac{\partial^{2} u_{r}}{\partial z^{2}}\right]-\left(\frac{1}{D a} \sqrt{\frac{\operatorname{Pr}}{R a}}+\frac{F o}{\sqrt{D a}}|\vec{u}|\right) u_{r} \\
& \frac{1}{\varepsilon} \frac{\partial u_{z}}{\partial t}+\frac{1}{\varepsilon^{2}}\left(u_{r} \frac{\partial u_{z}}{\partial r}+u_{z} \frac{\partial u_{z}}{\partial z}\right)=-\frac{\partial p_{f}}{\partial z}+ \\
& \sqrt{\frac{\operatorname{Pr}}{R a}} \frac{J}{\varepsilon}\left[\frac{1}{r} \frac{\partial}{\partial r}\left(r \frac{\partial u_{z}}{\partial r}\right)+\frac{\partial^{2} u_{z}}{\partial z^{2}}\right]-\left(\frac{1}{D a} \sqrt{\frac{\operatorname{Pr}}{R a}}+\frac{F o}{\sqrt{D a}}\right) u_{z}+T \\
& \sigma \frac{\partial T}{\partial t}+u_{r} \frac{\partial T}{\partial r}+u_{z} \frac{\partial T}{\partial z}=\frac{\lambda}{\sqrt{R a \operatorname{Pr}}}\left(\frac{1}{r} \frac{\partial}{\partial r}\left(\frac{\partial(r \cdot T)}{\partial r}\right)+\frac{\partial^{2} T}{\partial y^{2}}\right)
\end{aligned}
$$

The Boussinesq approximation is introduced to take into account the buoyancy effects and the thermo-physical parameters of the porous medium are calculated as geometrical mean values of fluid and solid phase. For the definition of the scales and parameters used to derive the dimensionless eqs. (1)-(4), the reader can refer to [26].

\section{NUMERICAL MODEL}

The set of governing Partial Differential Equations (PDEs) has been here discretized employing the fully explicit version of the Characteristic-Based Split (CBS) algorithm, known as
Artificial Compressibility (AC) CBS. In this scheme, the time discretization is based on the Characteristic Galerkin; in order to apply this stabilization technique to the momentum equations, a projection strategy is introduced in the CBS scheme by dividing the calculation into two stages. In the first one, the pressure term is dropped from the momentum equation and an intermediate velocity field is calculated by introducing the artificial compressibility parameter in the mass conservation equation: so, the pressure calculated at this step is an artificial quantity. In the second one, the intermediate velocities are corrected.

The standard Galerkin finite element method with linear triangular elements is employed for the spatial discretization.

Here, it is not reported the fully discretized form of the governing equations for the sake of brevity; the reader can refer to reference [26] for the detailed description of the numerical model. Further details on code validation, stability conditions and the derivation of the algorithm are available in references [28-31].

\section{RESULTS}

In this section, the numerical results, obtained for unsteady free convection in a tall annulus with the Aspect Ratio (AR) equal to $4: 1$, partially filled by a porous layer with variable properties and positions, are presented.

Several analyses have been performed considering three different geometrical configurations: a first one, in which the porous layer is located near the inner wall of the annulus (case A), a second one where the porous domain is at the center of the annulus (case B) and a last one, in which the porous medium is located near the outer wall of the annulus (case $\mathrm{C}$ ).

The different computational domains are shown in Figure 1, which also reports the thermal boundary conditions employed. For the velocity field, no-slip condition is applied to all boundaries, except to the interfaces between the porous medium and the free fluid, where the continuity of all physical quantities is imposed as a matching condition.

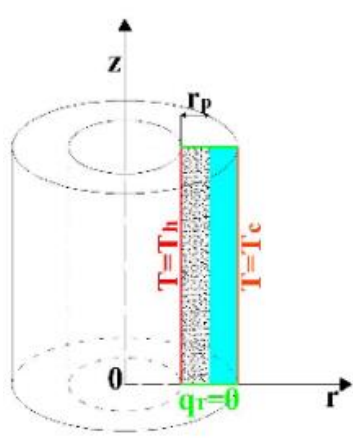

case $(A)$

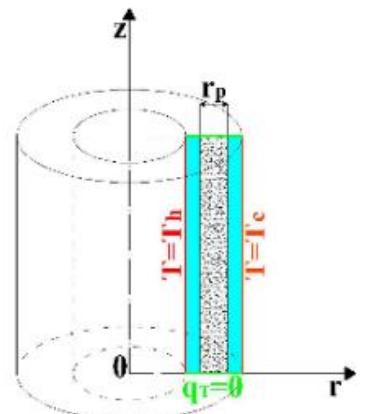

case (B)

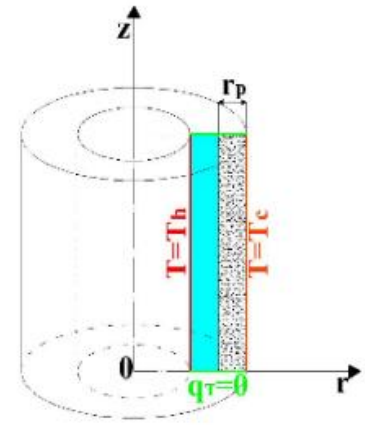

case (C)

Figure 1. Reference geometries and boundary conditions employed

Two different computational grids have been employed for the simulations: a first one, for case $\mathrm{A}$ and $\mathrm{C}$, composed of 18000 triangular elements and 9231 nodes, while the second one, employed for case B, consists of 19800 triangular elements and 10117 nodes. Both meshes, selected after an accurate grid sensitivity analysis, have been refined near all the boundaries to catch the local variations of the quantities of interest.
The following input parameters have been considered for all the simulations: $\operatorname{Pr}=0.71, \mathrm{Ra}=3.4 \cdot 10^{6}, \varepsilon=0.5$, Da ranging from $10^{-3}$ to $10^{-5}$. First, several simulations have been performed assuming a fixed thickness of the porous domain, $r_{p}=0.5$, and adopting a fixed annular reference geometry with a radii ratio $\mathrm{r}_{\mathrm{o}} / \mathrm{r}_{\mathrm{i}}=2$.

The final results in terms of temperature contours are shown in Figure 2 for all the geometrical configurations examined 
and the different values of Da employed: it is quite interesting to notice that for $\mathrm{Da}=10^{-3}$, the isotherms show similar trends for all the different cases under study, while for $\mathrm{Da} \leq 10^{-4}$, the temperature fields are strongly influenced by the properties and the position of the porous layer.

In order to analyze the transient behavior of the phenomenon, six probe points have been selected; their coordinates are reported in Table 1.

Table 1. Non dimensional coordinates of probe points

\begin{tabular}{ccc}
\hline Point & $\mathrm{r}$ & $\mathrm{z}$ \\
\hline $1-$ & $\mathrm{r}_{\mathrm{i}}+0.091$ & 3.685 \\
\hline $2-\cdots-\cdots-\cdots-\cdots$ & $\mathrm{r}_{\mathrm{i}}+0.910$ & 0.315 \\
\hline $3-------$ & $\mathrm{r}_{\mathrm{i}}+0.091$ & 0.315 \\
\hline $4-------$ & $\mathrm{r}_{\mathrm{i}}+0.910$ & 3.685 \\
\hline $5-\cdot-\cdot-\cdot-\cdots$ & $\mathrm{r}_{\mathrm{i}}+0.091$ & 2.000 \\
\hline $6 \cdots \cdots \cdots \cdots \cdots \cdots \cdots$ & $\mathrm{r}_{\mathrm{i}}+0.910$ & 2.000 \\
\hline
\end{tabular}

a)

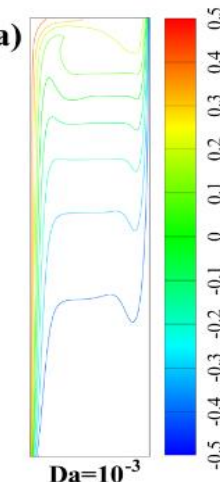

b)

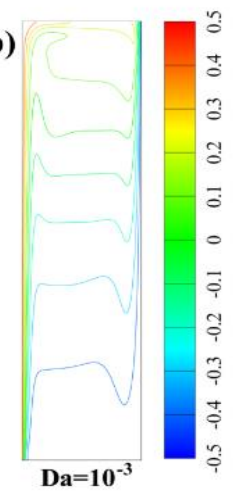

c)

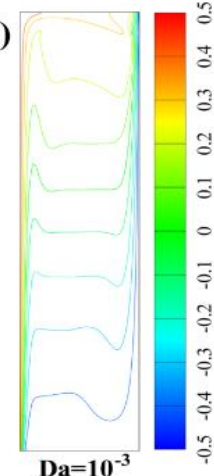

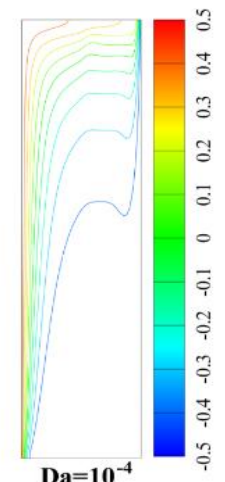

$\mathrm{Da}=10^{-4}$

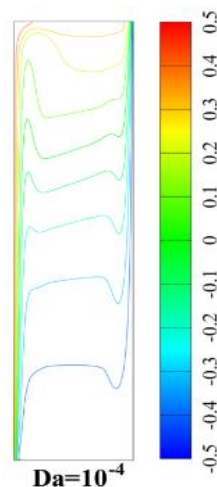

$\mathrm{Da}=10^{-4}$

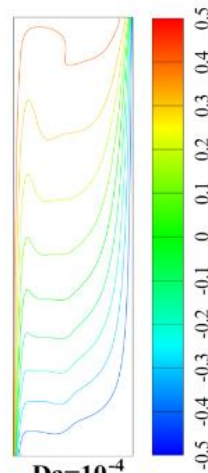

$\mathrm{Da}=10^{-4}$

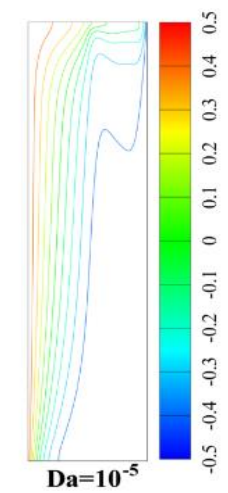

$\mathrm{Da}=10^{-5}$

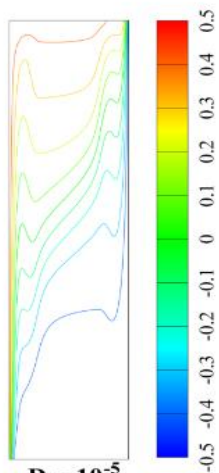

$\mathrm{Da}=10^{-5}$

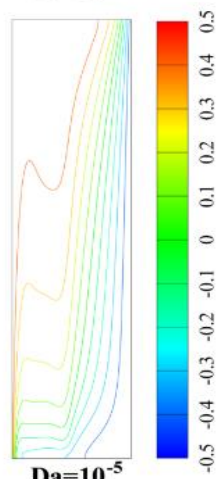

$\mathrm{Da}=10^{-5}$
Figure 2. Temperature contours at $\tau=500$ for different values of Da for: a) case A, b) case B, c) case C $\left(\mathrm{Ra}=3.4 \cdot 10^{6}, \mathrm{r}_{\mathrm{p}}=0.5, \mathrm{r}_{\mathrm{o}} / \mathrm{r}_{\mathrm{i}}=2\right)$
Figure 3 analyzes the transient evolution of temperature at probe points from 1 to 6 (see Table 1) for all three configurations and for two different values of Darcy: $\mathrm{Da}=10^{-3}$ (on the left) and $\mathrm{Da}=10^{-5}$ (on the right). The analysis of the results highlights that both the position and the permeability of the porous insert affect significantly the thermal transient behavior of the cavity: for $\mathrm{Da}=10^{-5}$ no transient oscillations of temperature field are observed for all the cases under study; whereas for $\mathrm{Da}=10^{-3}$ transient oscillations rises at different points of the cavity, depending on the different position of the porous insert into the cavity, but dampen with the time in all the cases.
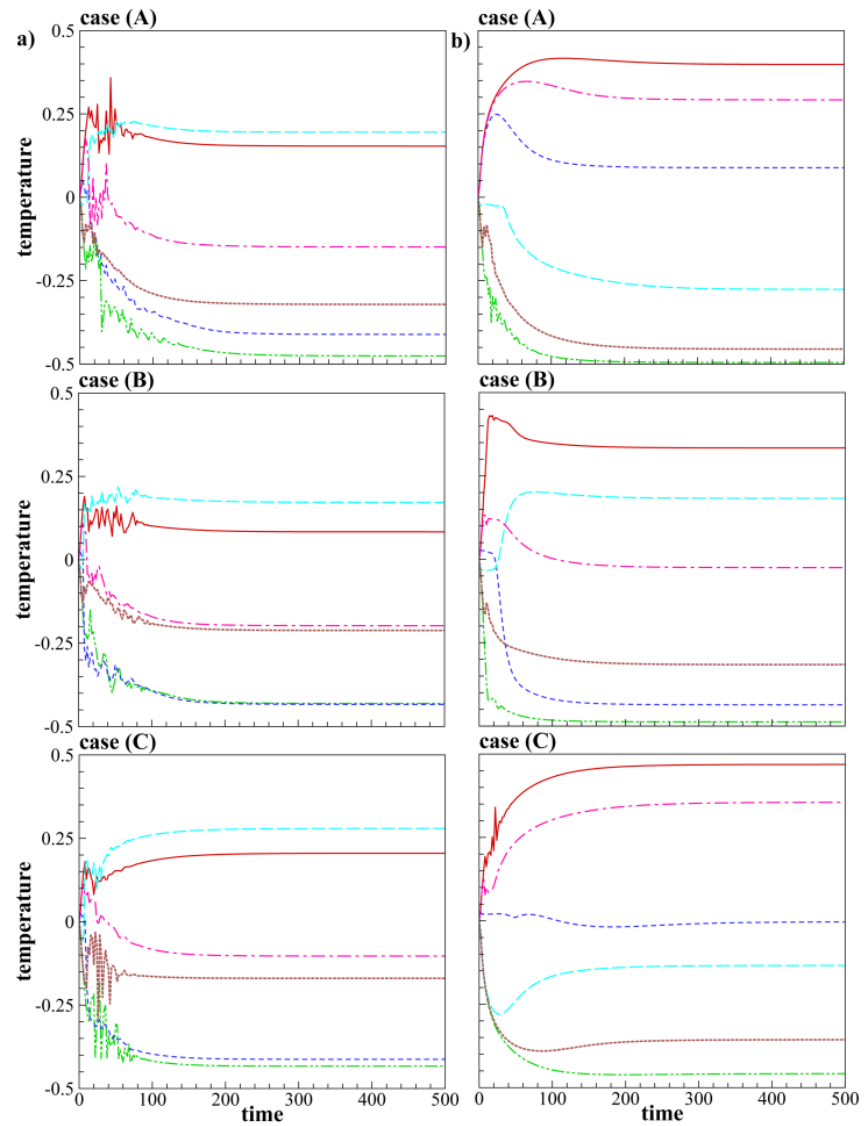

Figure 3. Transient evolution of temperature for $\mathrm{Da}=10^{-3}$ (on the left) and $\mathrm{Da}=10^{-5}$ (on the right) at six probe points (see Table 1) for $\mathrm{Ra}=3.6 \cdot 10^{6}$ for the different cases under study

$$
\left(\mathrm{r}_{\mathrm{p}}=0.5, \mathrm{r}_{\mathrm{o}} / \mathrm{r}_{\mathrm{i}}=2\right.
$$

Moreover, several simulations have been performed assuming a fixed thickness of porous layer $\left(r_{p}=0.5\right)$ for the three configurations $\mathrm{A}, \mathrm{B}$ and $\mathrm{C}$, and a cavity radii ratio $\mathrm{r}_{\mathrm{o}} / \mathrm{r}_{\mathrm{i}}$ variable into the range $1.5 \div 5$, considering different values of Da ranging from $10^{-3}$ to $10^{-5}$. Transient evolution of temperature at the six probe points has been represented in Figures 4-6: in particular, Figures 4, 5 and 6 represent the results related to case $\mathrm{A}, \mathrm{B}$ and $\mathrm{C}$, respectively, for $\mathrm{Da}=10^{-3}$ (on the left) and for $\mathrm{Da}=10^{-5}$ (on the right). For high values of $\mathrm{Da}$, the value of the radii ratio affects the time evolution of temperature, as the amplitude of the transient oscillations decreases with the increase of the radii ratio for all the configuration studied; for low values of $\mathrm{Da}$, the radii ratio affects the transient temperature distribution into the cavity but has not a strong influence on the transient evolution of the fluid flow at the six probe points examined. 

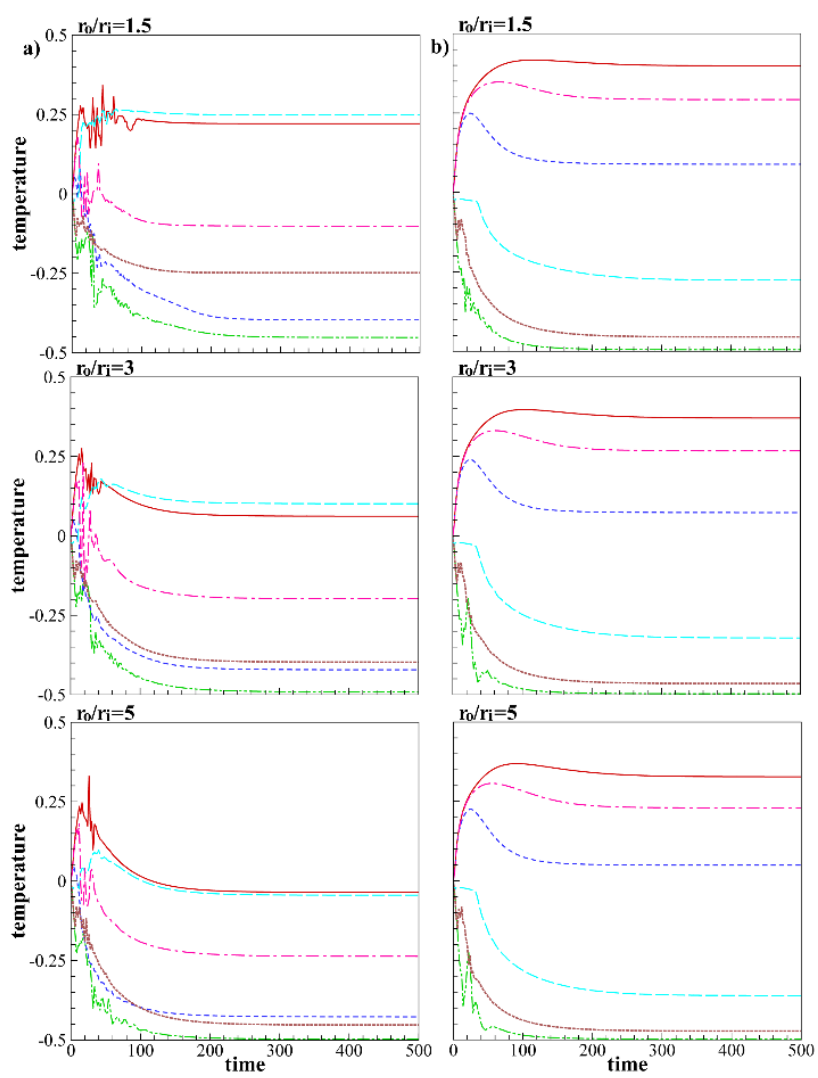

Figure 4. Transient evolution of temperature for $\mathrm{Da}=10^{-3}$ (on the left) and $\mathrm{Da}=10^{-5}$ (on the right) at probe points from 1 to 6 for several values of $r_{o} / r_{i}\left(R a=3.4 \cdot 10^{6}, r_{p}=0.5\right.$, case A)
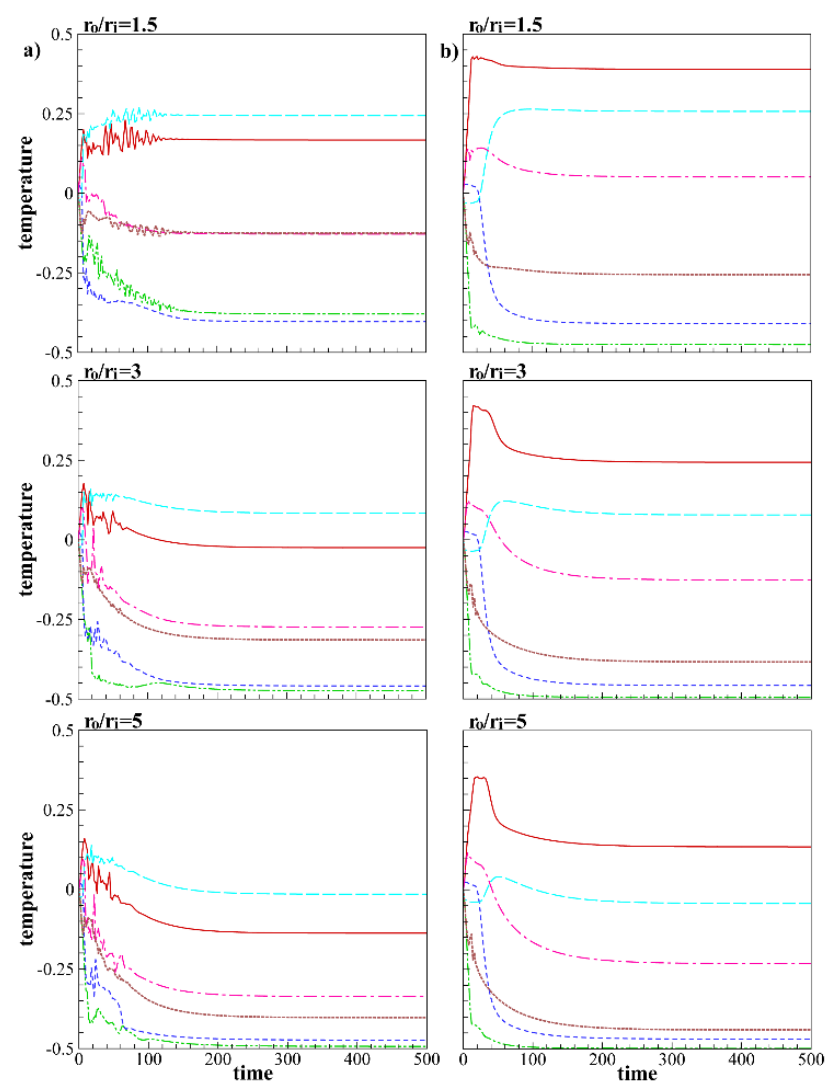

Figure 5. Transient evolution of temperature for $\mathrm{Da}=10^{-3}$ (on the left) and $\mathrm{Da}=10^{-5}$ (on the right) at probe points from 1 to 6 for several values of $r_{o} / r_{i}\left(R a=3.4 \cdot 10^{6}, r_{p}=0.5\right.$, case $\left.B\right)$

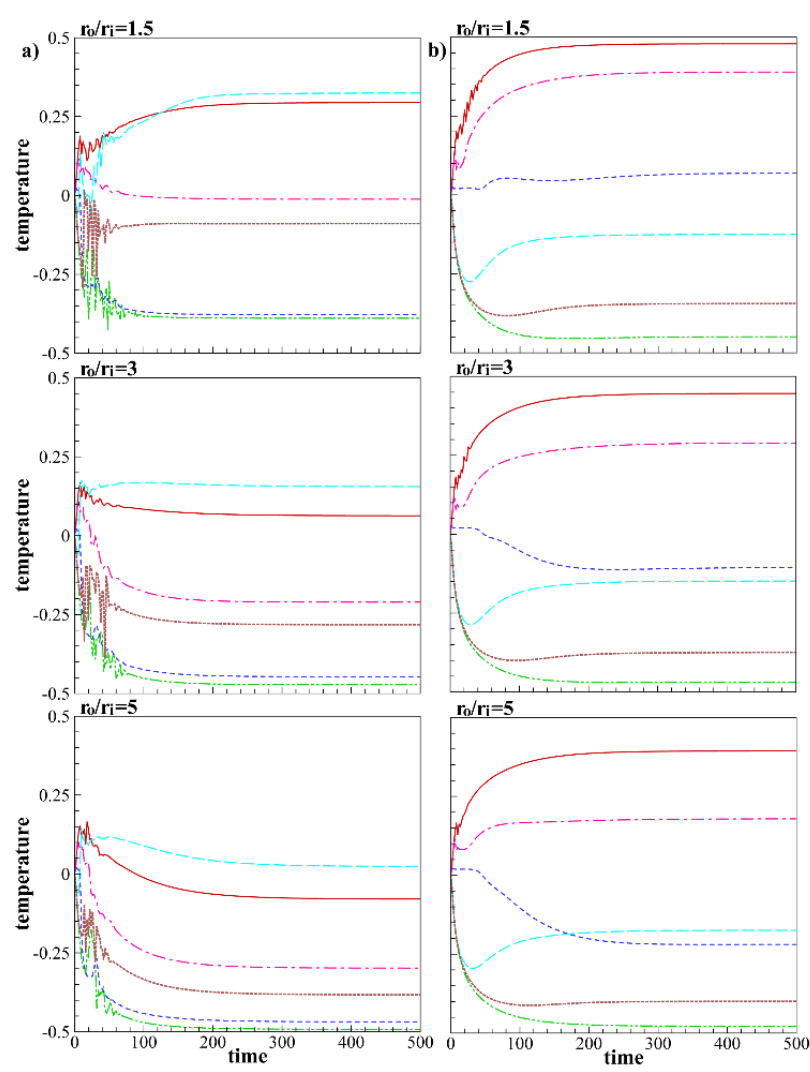

Figure 6. Transient evolution of temperature for $\mathrm{Da}=10^{-3}$ (on the left) and $\mathrm{Da}=10^{-5}$ (on the right) at probe points from 1 to 6 for several values of $r_{\mathrm{o}} / \mathrm{r}_{\mathrm{i}}\left(\mathrm{Ra}=3.4 \cdot 10^{6}, \mathrm{r}_{\mathrm{p}}=0.5\right.$, case $\left.\mathrm{C}\right)$
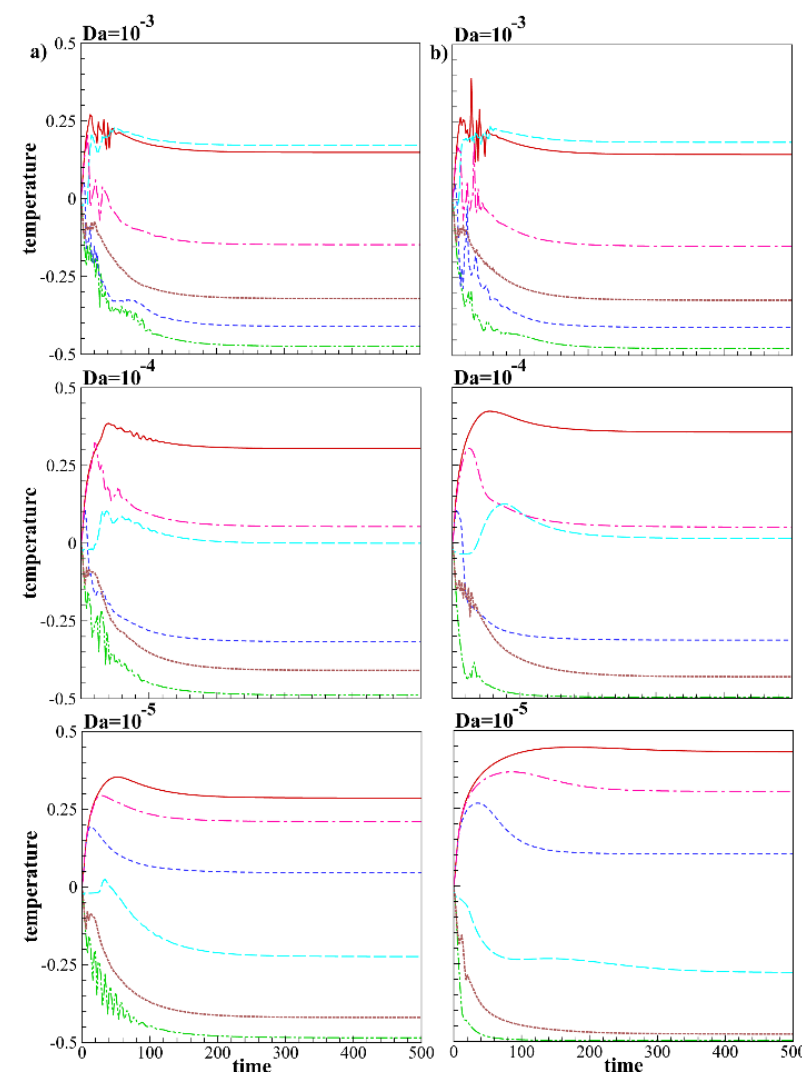

Figure 7. Transient evolution of temperature at probe points from 1 to 6 in a 4:1 partially porous annulus (case A) for Da ranging from $10^{-3}$ to $10^{-5}$, for: a) $r_{p}=0.25$ and $\left.b\right) r_{p}=0.75$ $\left(\mathrm{Ra}=3.4 \cdot 10^{6}, \mathrm{r}_{\mathrm{o}} / \mathrm{r}_{\mathrm{i}}=2\right)$ 

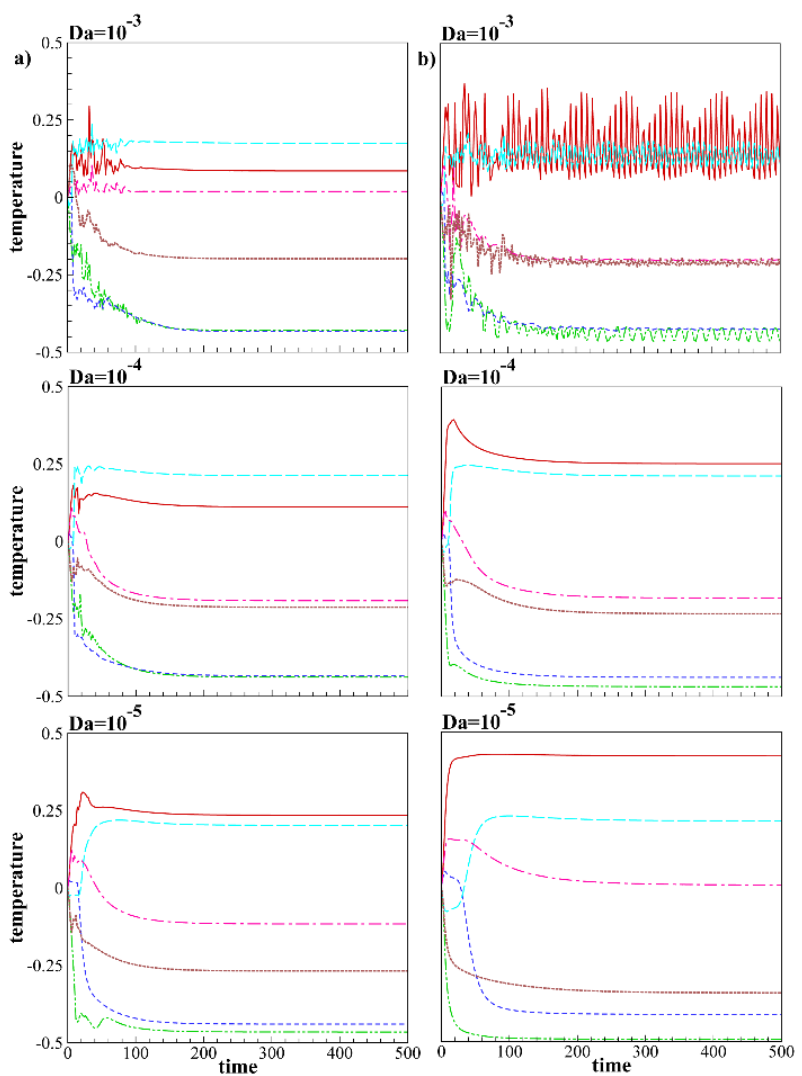

Figure 8. Transient evolution of temperature at probe points from 1 to 6 in a 4:1 partially porous annulus (case B) for Da ranging from $10^{-3}$ to $10^{-5}$, for: a) $r_{p}=0.25$ and b) $r_{p}=0.75$

$$
\left(\mathrm{Ra}=3.4 \cdot 10^{6}, \mathrm{r}_{\mathrm{o}} / \mathrm{r}_{\mathrm{i}}=2\right)
$$
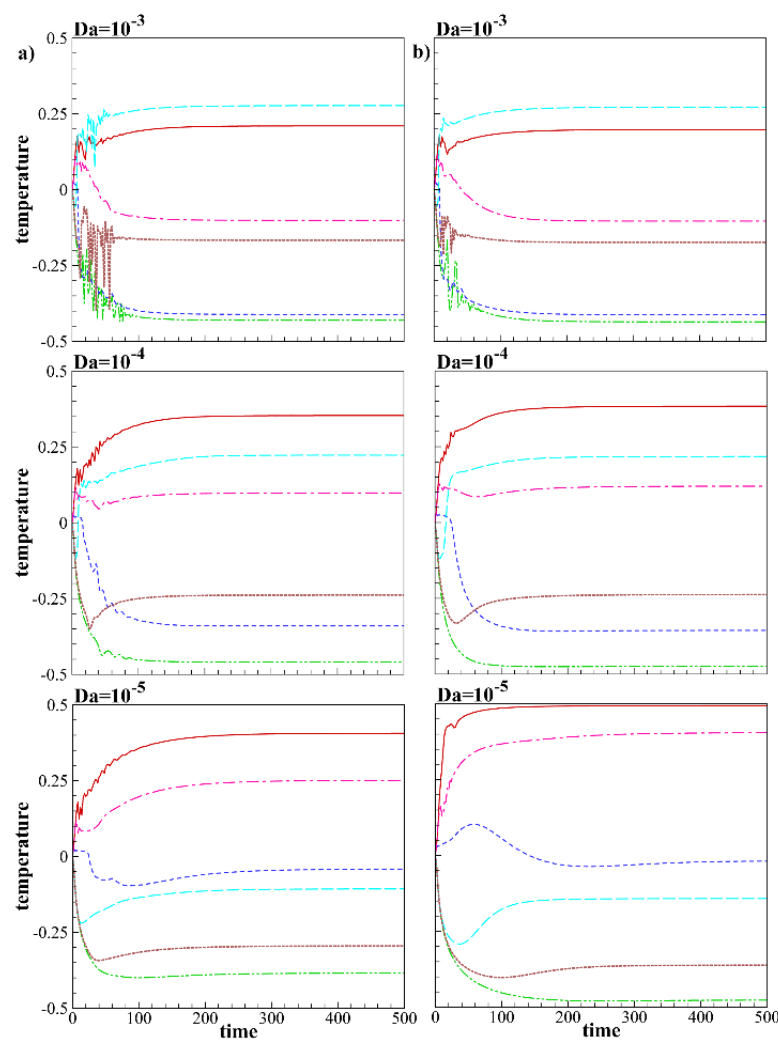

Figure 9. Transient evolution of temperature at probe points from 1 to 6 in a 4:1 partially porous annulus (case C) for $\mathrm{Da}$ ranging from $10^{-3}$ to $10^{-5}$, for: a) $r_{p}=0.25$ and $b$ ) $r_{p}=0.75$ $\left(\mathrm{Ra}=3.4 \cdot 10^{6}, \mathrm{r}_{\mathrm{o}} / \mathrm{r}_{\mathrm{i}}=2\right)$
Finally, several analyses have been conducted by assuming a fixed value of radii ratio, $r_{0} / r_{i}=2$ for the three configurations shown in Fig. 1, and a variable thickness of the porous layer, $\mathrm{r}_{\mathrm{p}}$, considering different values of Da numbers, ranging from $10^{-3}$ to $10^{-5}$. Figures 7-9 show the variation of the temperature over the time at the probe points from 1 to 6 , for case A (Figure 7), case B (Figure 8) and case C (Figure 9). All the Figures report on the left side the results related to $r_{p}=0.25$, whereas on the right side are represented the transient evolution observed for $r_{p}=0.75$. The analyses of the results highlight that the porous layer thickness strongly affects the transient evolution of the temperature into the cavity for $\mathrm{Da}=10^{-3}$; this is true for all the configurations examined here, as transient oscillations of different amplitude characterize the temporal evolution of the convective phenomenon for variable values of $r_{p}$. In particular, the amplitude of these oscillations rises with the increase of $r_{p}$; moreover, the configuration $B$ is the one that is more affected by the porous layer thickness, as a periodic oscillating behavior with respect to time characterizes the transient evolution of the convection into the cavity only for $\mathrm{r}_{\mathrm{p}}=0.75$.

\section{CONCLUSIONS}

In this paper, a fully explicit version of the CBS scheme has been applied to the analysis of the transient evolution of natural convection in partially porous annuli in presence of large source terms.

The generalized porous medium model has been applied and several analyses have been conducted by changing both the position and the thickness of the porous layer, both its physical properties and the cavity geometry, by considering a Da number variable into the range $10^{-3}-10^{-5}$ and a value of Rayleigh number equal to $3.4 \cdot 10^{6}$

The numerical results underline that the insertion of a porous layer strongly affects the transient evolution of the convective phenomena into the enclosure. In fact, a transient oscillating behavior of different amplitude and length appears in the cavity depending on both geometrical and physical properties of the porous medium. For all the cases analyzed, the amplitude of the oscillating phenomenon decreases with the Da number.

\section{REFERENCES}

[1] Kaviany M. (1995). Principles of Heat Transfer in Porous Media, Springer, New York.

[2] Nield D.A., Bejan A. (1999). Convection in Porous Media, 2 ed., Springer, New York.

[3] Reda D.C. (1983). Natural convection experiments in a liquid-saturated porous medium bounded by vertical coaxial cylinders, ASME J. Heat Transf., Vol. 105, No. 4, pp. 795-802. DOI: 10.1115/1.3246987

[4] Prasad V., Kulacki F.A., Keyhani M. (1985). Natural convection in porous media, J. Fluid Mech., Vol. 150, pp. 89-119. DOI: $10.1017 / \mathrm{s} 0022112085000040$

[5] Prasad V., Kulacki F.A., Kulkarni A.V. (1986). Free convection in a vertical porous annulus with constant heat flux on the inner wall-experimental results, Int. J. Heat Mass Transf., Vol. 29, No. 5, pp. 713-723. DOI: $\underline{10.1016 / 0017-9310(86) 90123-7}$ 
[6] Havstad M.A., Burns P.J. (1982). Convective heat transfer in vertical cylindrical annuli filled with a porous medium, Int. J. Heat Mass Transf., Vol. 25, No. 11 , pp. 1755-1766, 1982. DOI: $10.1016 / 0017-$ 9310(82)90155-7

[7] Prasad V., Kulacki F.A. (1985). Natural convection in porous media bounded by short concentric vertical cylinders, J. Heat Transf., Vol. 107, No. 1, pp. 147-154. DOI: $\underline{10.1115 / 1.3247371}$

[8] Prasad V. (1986). Numerical study of natural convection in a vertical, porous annulus with constant heat flux on the inner wall, Int. J. Heat Mass Transf., Vol. 29, No. 6, pp. 841-853. DOI: 10.1016/00179310(86)90180-8

[9] Hickox C.E., Gartling D.K. (1985). A numerical study of natural convection in a vertical annular porous layer, Int. J. Heat Mass Transf., Vol. 28, No. 3, pp. 720-723. DOI: $10.1016 / 0017-9310(85) 90196-6$

[10] Badruddin I.A., Zainal Z.A., Kahn Z.A., Mallick Z. (2007). Effect of viscous dissipation and radiation on natural convection in a porous medium embedded within vertical annulus, Int. J. Therm. Sci., Vol. 46, No. 3, pp. 221-227, 2007. DOI: $\underline{10.1016 / \text { j.ijthermalsci.2006.05.005 }}$

[11] Badruddin I.A., Zainal Z.A., Aswatha Narayana, P.A., Seetharamu K.N. (2006). Heat transfer by radiation and natural convection through a vertical annulus embedded in porous medium, Int. Commun. Heat Mass Transf., Vol. 33, No. 4, pp. 500-507. DOI: 10.1016/j.icheatmasstransfer.2006.01.008

[12] Badruddin I.A., Zainal Z.A, Narayana P.A.A., Seetharamu K.N. (2006). Thermal non-equilibrium modeling of heat transfer through vertical annulus embedded with porous medium, Int. J. Heat Mass Transf., Vol. 49, No. 25, pp. 4955-4965. DOI: j.ijheatmasstransfer.2006.05.043

[13] Hasnaoui M., Vasseur P., Bilgen E., Robillard L. (1995). Analytical and numerical study of natural convection heat transfer in a vertical porous annulus, Chem. Eng. Commun., Vol. 131, No. 1, pp. 141-159. DOI: 10.1080/00986449508936288

[14] Prasanna B.M.R., Venkatachalappa M. (2003). Numerical study of natural convection in a vertical cylindrical annulus using a non-Darcy equation, $J$. Porous Media, Vol. 5, No. 2, pp. 87-102. DOI: 10.1615/JPorMedia.v5.i2.20

[15] Jha B.K. (2005). Free-convection flow through an annular porous medium, Heat Mass Transf., Vol. 41, No. 8, pp. 675-679. DOI: 10.1007/s00231-003-0469-1

[16] Rong F., Guo Z., Chai Z., Shi B. (2010). Lattice Boltzmann model for axisymmetric thermal flows through porous media, Int. J. Heat Mass Transf., Vol. 53, No. 23, pp. 5519-5527. DOI: 10.1016/j.ijheatmasstransfer.2010.07.005

[17] Char M.I., Lee G.C. (1998). Maximum density effects on natural convection in a vertical annulus filled with a non-Darcy porous medium, Acta Mech., Vol. 128, No. 3, pp. 217-231. DOI: 10.1007/BF01251892

[18] Marpu D.R. (1995). Forchheimer and Brinkman extended Darcy flow model on natural convection in a vertical cylindrical porous annulus, Acta Mech., Vol. 109, No. 1-4, pp. 41-48. DOI: 10.1007/BF01176815

[19] Sankar M., Park Y., Lopez J.M., Do Y. (2011). Numerical study of natural convection in a vertical porous annulus with discrete heating, Int. J. Heat Mass Transf., Vol. 54, No. 7, pp. 1493-1505. DOI: j.ijheatmasstransfer.2010.11.043

[20] Jha B.K., Yusuf T.S. (2016). Transient free convective flow in an annular porous medium: A semi-analytical approach, Eng. Sci. Tech. Int. J., Vol. 16, No. 4, pp. 1936-1948. DOI: 10.1016/j.jestch.2016.09.022

[21] Kiwan S., Al-Zahrani M.S. (2008). Effect of using porous inserts on natural convection heat transfer between two concentric vertical cylinders, Numer. Heat Transf. Part A: Appl., Vol. 53, No. 8, pp. 870-889. DOI: 10.1080/10407780701715869

[22] Benzeghiba M., Chikh S., Campo A. (2003). Thermosolutal convection in a partly porous vertical annular cavity, J. Heat Transf.-Trans. ASME, Vol. 125, No. 4, pp. 703-715. DOI: $10.1115 / 1.1589501$

[23] Reddy P.V., Narasimham G.S.V.L. (2008). Natural convection in a vertical annulus driven by a central heat generating rod, Int. J. Heat Mass Transf., Vol. 51, No. 19, pp. 5024-5032. DOI: 10.1016/j.ijheatmasstransfer.2008.02.032

[24] Arpino F., Carotenuto A., Massarotti N., Mauro A. (2013). New solutions for axial flow convection in porous and partly porous cylindrical domains, Int. J. Heat Mass Transf., Vol. 57, No. 1, pp. 155-170. DOI: 10.1016/j.ijheatmasstransfer.2012.10.030

[25] Al-Nimr M.A., Khadrawi F. (2003). Transient free convection fluid flow in domains partially filled with porous media, Transp. Porous Media, Vol. 51, No. 2, pp. 157-172. DOI: $10.1023 / \mathrm{A}: 1021999806585$

[26] Massarotti N., Ciccolella M., Cortellessa G., Mauro A. (2016). New benchmark solutions for transient natural convection in partially porous annuli, Int. J. Numer. Meth. Heat \& Fluid Flow, Vol. 26, No. 3-4., pp. $1187-$ 1225. DOI: 10.1108/HFF-11-2015-0464

[27] Whitaker S. (1996). The Forchheimer equation: A theoritical development, Trans. Porous Media, Vol. 25, No. 1, pp. 27-61. DOI: 10.1007/BF00141261

[28] Arpino F., Ciccolella M., Cortellessa G., Massarotti N., Mauro A. (2016). Transient Natural Convection in Partially Porous Annuli, Int. J. Heat Tech., Vol. 34, pp. S512-S516. DOI: 10.18280/ijht.34S2

[29] Arpino F., Massarotti N., Mauro A. (2011). Efficient three-dimensional FEM based algorithm for the solution of convection in partly porous domains, Int. J. Heat Mass Transf., Vol. 54, No. 21, pp. 4495-4506. DOI: 10.1016/j.ijheatmasstransfer.2011.06.030

[30] Arpino F., Cortellessa G., Dell'Isola M., Massarotti N., Mauro A. (2014). High order explicit solutions for the transient natural convection of incompressible fluids in tall cavities, Numer. Heat Transf., Part A: Appl., Vol. 66, No. 8, pp. 839-862. DOI: 10.1080/10407782.2014.892389

[31] Arpino F., Cortellessa G., Mauro A. (2015). Transient thermal analysis of natural convection in porous and partially porous cavities, Numer. Heat Transf., Part A: Appl., Vol. 67, No. 6, pp. 605-631. DOI: $\underline{10.1080 / 10407782.2014 .949133}$

\section{NOMENCLATURE}

AR aspect ratio

$\mathrm{B}_{\mathrm{f}} \quad$ isobaric compressibility of fluid $\mathrm{K}^{-1}$ 
$\mathrm{c}_{\mathrm{p}} \quad$ specific heat, $\mathrm{J} \cdot \mathrm{kg}^{-1} \cdot \mathrm{K}^{-1}$

$\mathrm{Da} \quad$ Darcy number, $\mathrm{Da}=\kappa \cdot \mathrm{L}^{-2}$

Fo Forchheimer coefficient,

$$
F o=1.75 \cdot(\sqrt{150})^{-1} \cdot \varepsilon^{-3 / 2}
$$

g gravitational acceleration, $\mathrm{m} \cdot \mathrm{s}^{-2}$

$\mathrm{J} \quad$ viscosity ratio, $J=\mu_{e f f} \cdot \mu_{f}^{-1}$

$\mathrm{L} \quad$ characteristic length

$\mathrm{p}$ pressure, $\mathrm{Pa}$

Pr Prandtl number $\operatorname{Pr}=v_{f} \cdot \alpha_{f}^{-1}$

$\mathrm{r}$ radial coordinate, $\mathrm{m}$

$\mathrm{Ra} \quad$ Rayleigh number,

$$
R a=g \cdot B_{f} \cdot\left(T_{h}^{*}-T_{c}^{*}\right) \cdot L^{3} \cdot v_{f}^{-1} \cdot \alpha_{f}^{-1}
$$

$\mathrm{t}$ real time, $\mathrm{s}$

$\mathrm{T}$ temperature, ${ }^{\circ} \mathrm{C}$

$\vec{u} \quad$ velocity vector, $\mathrm{m} \cdot \mathrm{s}^{-1}$

$\mathrm{u}_{\mathrm{i}} \quad$ seepage velocity components, $\mathrm{m} \cdot \mathrm{s}^{-1}$

$\mathrm{z} \quad$ vertical coordinate

\section{Greek symbols}

$\alpha \quad$ thermal diffusivity, $\mathrm{m}^{2} \cdot \mathrm{s}^{-1}$

$\varepsilon \quad$ porosity

$\kappa \quad$ intrinsic permeability, $\mathrm{m}^{2}$

$\lambda \quad$ thermal conductivity, $\mathrm{W} \cdot \mathrm{m}^{-1} \cdot \mathrm{K}^{-1}$

$\mu \quad$ dynamic viscosity, $\mathrm{kg} \cdot \mathrm{m}^{-1} \cdot \mathrm{s}^{-1}$

$v \quad$ kinematic viscosity, $\mathrm{m}^{2} \cdot \mathrm{s}^{-1}$

$\rho \quad$ density, $\mathrm{kg} \cdot \mathrm{m}^{-3}$

$\alpha \quad$ thermal diffusivity, $\mathrm{m}^{2} \cdot \mathrm{s}^{-1}$

\section{Subscripts}

$\begin{array}{ll}\text { c } & \text { cold } \\ \text { eff } & \text { effective } \\ \text { f } & \text { fluid } \\ \text { h } & \text { hot } \\ \text { r } & \text { radial component } \\ \text { z } & \text { vertical component }\end{array}$

\section{Superscripts}

* dimensional quantities 